\title{
A comparative study on the ranking performance of some multi-criteria decision-making methods for industrial robot selection
}

\author{
Vijay Manikrao Athawale ${ }^{\mathrm{a}}$ and Shankar Chakraborty ${ }^{\mathrm{b}^{*}}$
}

${ }^{a}$ Department of Mechanical Engineering, Government Polytechnic, Amravati 4444603 , India

${ }^{b}$ Department of Production Engineering, Jadavpur University, Kolkata - 700 032, India

\begin{tabular}{l}
\hline A R T I C L E I N F O \\
\hline Article history: \\
Received 1 April 2011 \\
Received in revised form \\
May, 08, 2011 \\
Accepted 08 May 2011 \\
Available online \\
10 May 2011 \\
\hline Keywords: \\
Robot selection \\
MCDM method \\
Ranking performance \\
Spearman's rank correlation \\
coefficient \\
Kendall's coefficient of \\
concordance
\end{tabular}

\section{Introduction}

An industrial robot is a reprogrammable multifunctional manipulator designed to move materials, parts, tools or other devices by means of variable programmed motions and to perform a variety of other tasks (Rao, 2007). Industrial robots can perform repetitious, difficult and hazardous tasks (like assembly, machine loading, material handling, spray painting and welding) with precision, and can also significantly improve quality and productivity of the manufacturing organizations. Robots with varying capabilities and specifications are now available in the market dedicated to perform a wide range of operations. Selection of the robot to suit a particular application and manufacturing environment from a large number of candidate alternatives has now become a challenging task. Since a huge amount of initial investment is required for robot acquisition and installation, appropriate robot selection calls for a careful examination and assessment of the requirements as well as characteristics of the alternatives, which is a process that can only be achieved from the use of quantitative tools. The complexity of the problem can be better understood when one realizes that there are over 75 attributes that are to be considered while selecting a robot for a particular industrial application (Bhangale et al., 2004). Among these attributes, cost, load carrying capacity, velocity, weight of the robot, material of robot, drive systems, size of the robot, accuracy of the robot,

\footnotetext{
* Corresponding author. Tel.: +091-033-2414-6153

E-mail: s_chakraborty00@yahoo.co.in (S. Chakraborty)

(C) 2011 Growing Science Ltd. All rights reserved.

doi: $10.5267 / j$. ijiec.2011.05.002
}

\begin{abstract}
Industrial robots are mainly employed to perform repetitive and hazardous production jobs, multi-shift operations etc. to reduce the delivery time, improve the work environment, lower the
production cost and even increase the product range to fulfill the customers' needs. When a choice is to be made from among several alternative robots for a given industrial application, it is necessary to compare their performance characteristics in a decisive way. As the industrial alternatives, different multi-criteria decision-making (MCDM) methods can be effectively used ty so problem. In this paper, ten most popular MCDM methods are considered robots as engaged in some industrial pick-n-place operation. It is observed that all these methods give almost the same rankings of the alternative robots, although the performance of for a given industrial robot selection problem, more attention is to be paid on the proper selection of the relevant criteria and alternatives, not on choosing the most appropriate MCDM method to be employed.
\end{abstract}


geometrical dexterity, path measuring systems, programming flexibility, man-machine interface and availability of the diagnostic software are considered to be the most important ones. Many of these attributes are conflicting in nature and have different units, which cannot be unified and compared as they are. Thus, the decision makers are experiencing difficulties in determining the most suitable robot alternative due to the involvement of a large number of conflicting and non-commensurate robot performance characteristics.

Although a good amount of research work has been carried out in the past on solving industrial robot selection problems using different mathematical approaches, specially employing multi-criteria decision-making (MCDM) methods, very little attempt has been made to compare the relative performance of the MCDM methods while solving the decision-making problems. This paper mainly focuses on comparing the relative performance of ten most well-known MCDM methods with respect to the observed rankings of the alternative robots for a given pick-n-place operation (Bhangale et al., 2004). In this paper, attempts are made to find the answers of the questions, like a) Which MCDM method is more appropriate for solving the industrial robot selection problem? and b) Does the best robot selection decision change while using different MCDM methods?

\section{Literature review}

Agrawal et al. (1991) proposed a robot selection procedure to rank the alternatives in a shortlist by employing TOPSIS (technique for order preference by similarity to ideal solution) method. An expert system was also developed to assist the decision maker to establish priorities and visualize the selection process at various stages. Khouja (1995) applied data envelopment analysis (DEA) to identify the robots with the best combination of vendor specifications based on the robot performance parameters. Then, a multi-attribute decision-making method was adopted to select the best robot. Zhao et al. (1996) combined a multi-chromosome genetic algorithm with first-fit bin packing algorithm for solving the robot selection and workstation assignment problems for a computer integrated manufacturing system. Goh et al. (1996) developed a revised weighted sum decision model taking into account both the objective and subjective attributes while selecting a robot for an industrial application. Baker and Talluri (1997) proposed an industrial robot selection methodology based on cross efficiencies in DEA without considering the criteria weights or the decision maker's preferences. Goh (1997) applied analytic hierarchy process (AHP) for robot selection that could simultaneously consider both the objective and subjective attributes. Braglia and Petroni (1999) proposed a methodology for selection of industrial robots using DEA which aims at identification of the best robot by measuring the relative efficiency for each robot through the resolution of linear programming problems. Parkan and Wu (1999) presented the applications and interrelationship of the operational competitiveness rating and TOPSIS methods in a robot selection problem, and compared their performance with other approaches. Khouja and Kumar (1999) proposed a robot selection model, which would, in turn, give the decision maker the option of replacing the selected robot with a better one during the life of products with uncertain demand. Braglia and Gabbrielli (2000) considered the applicability of a mathematical method based on dimensional analysis theory to robot selection problems. Talluri and Yoon (2000) utilized a combination of the cone-ratio DEA which would integrate the decision maker's preferences, and a new methodological extension in DEA for selection of industrial robots. Chu and Lin (2003) proposed a fuzzy TOPSIS method for robot selection, where the ratings of various alternatives with respect to different subjective criteria and the weights of all the criteria had been assessed using fuzzy numbers. Bhangale et al. (2004) presented a robot selection methodology using TOPSIS and graphical methods, and compared the relative rankings of the alternative robots as derived using those two methods. Bhattacharya et al. (2005) integrated AHP and quality function deployment (QFD) methods for solving industrial robot selection problems, while considering seven technical requirements and four alternative robots. Karsak and Ahiska (2005) applied a practical common weight MCDM methodology with an improved discriminating power for robot selection. It was observed that the proposed methodology could enable further ranking of the DEA-efficient decision-making units with a notable saving in 
computations compared with cross-efficiency analysis. Rao and Padmanabhan (2006) employed the diagraph and matrix methods for evaluating and ranking of the alternative robots for a given industrial application. Kahraman et al. (2007) developed a hierarchical fuzzy TOPSIS method to solve the multi-attribute robot selection problems. Karsak (2008) proposed a decision model for robot selection based on QFD and fuzzy linear regression methods while integrating the user demands with the technical characteristics of the robots. Chatterjee et al. (2010) applied two MCDM methods, i.e. VIKOR (VIse Kriterijumska Optimizacija kompromisno Resenje) and ELECTRE II (ELimination and Et Choice Translating REality) to solve robot selection problems. Kumar and Garg (2010) proposed a deterministic quantitative model based on distance-based approach for evaluation, selection and ranking of robots. Koulouriotis and Ketipi (2011) developed a fuzzy digraph method for robot evaluation and selection according to a given industrial application. Singh and Rao (2011) developed a hybrid decision-making technique combining graph theory and matrix approach, and AHP method. Kentli and Kar (2011) applied satisfaction function and a distance measure technique for solving the robot selection problems. Rao et al. (2011) proposed a subjective and objective integrated multiple attribute decision-making method for robot selection.

Karni et al. (1990) applied AHP, simple additive weighting (SAW), ELECTRE and weighted linear assignment method (WLAM) to three real time cases and observed that the AHP, SAW and ELECTRE rankings did not differ significantly, however, the WLAM would tend to exhibit more disagreement. Guitouni and Martel (1998) proposed a conceptual framework for articulating tentative guidelines to choose an appropriate MCDM method and presented the results of the comparison of some well-known multi-criteria aggregation procedures on the basis of these guidelines. Zanakis et al. (1998) compared the performance of eight MCDM methods, e.g. ELECTRE, TOPSIS, multiplicative exponential weighting (MEW), SAW and four versions of AHP (original vs. geometric scale and right eigenvector vs. mean transformation solution), and observed that all the AHP versions behaved similarly and closer to SAW than the other methods. ELECTRE was the least similar to SAW, followed by MEW. TOPSIS behaved closer to AHP and differently from ELECTRE and MEW, except for problems with few criteria. Raju and Pillai (1999) compared the ranking performance of some MCDM methods, e.g. ELECTRE II, preference ranking organization method for enrichment evaluation (PROMETHEE II), AHP, compromise programming (CP) and EXPROM II (extension of PROMETHEE II in distance- based environment) using Spearman's rank correlation coefficient value. Hajkowicz and Higgins (2008) employed SAW, range of value method, PROMTHEE II, Evamix and CP to six water management decision problems, and suggested that more emphasis has to be given on the initial structuring of the decision problem, involving choosing the relevant criteria and alternative decisions. Caterino et al. (2009) compared the relative performance of eight MCDM methods, e.g. TOPSIS, weighted sum method, weighted product method, ELECTRE, multi-attribute utility theory, VIKOR, PROMETHEE I and PROMETHEE II for seismic retrofit of structures. TOPSIS and VIKOR methods seemed to be more appropriate for solving the retrofit selection problem because they are more capable to deal with each kind of judgment criteria, having clarity of results and easiness to deal with attributes and decision options.

\section{MCDM methods}

Multi-criteria decision-making refers to making decisions in the presence of multiple conflicting criteria. An MCDM method ranks the alternatives and the highest ranked one is recommended as the best alternative to the decision maker. In strategic planning, various MCDM methods are presently being applied which can also be effectively used to select the most appropriate robot for a given industrial application. But the vast array of available MCDM methods, of varying complexity and possibly solutions, confuses the potential decision maker. Several MCDM methods may appear to be suitable for a particular robot selection problem. Hence, the decision maker also faces the problem of selecting the most appropriate MCDM method from among several feasible alternatives.

The performance of different MCDM methods may be compared along varied dimensions, such as perceived simplicity, trustworthiness, robustness and quality. In this paper, in order to compare the 
ranking performance of different MCDM methods while solving a pick-n-place type of industrial robot selection problem, the following ten MCDM methods are considered.

a) Simple Additive Weighting (SAW) method,

b) Weighted Product Method (WPM),

c) Analytic Hierarchy Process (AHP),

d) Technique for Order Preference by Similarity to Ideal Solution (TOPSIS) method,

e) Graph Theory and Matrix Approach (GTMA),

f) VIKOR (VIse Kriterijumska Optimizacija kompromisno Resenje) method,

g) ELECTRE II (ELimination and Et Choice Translating REality) method,

h) PROMETHEE II (Preference Ranking Organization METHod for Enrichment Evaluation),

i) Grey Relational Analysis (GRA), and

j) Range of Value Method (ROVM).

The computational details of these MCDM methods are presented here-in-under.

\subsection{Simple additive weighting method}

Any MCDM problem can be represented by a matrix (X) consisting of $\mathrm{m}$ alternatives and $\mathrm{n}$ criteria.

$$
X=\left[\begin{array}{ccc}
x_{11} & \cdots & x_{1 n} \\
\vdots & \vdots & \vdots \\
x_{m 1} & \cdots & x_{m n}
\end{array}\right],
$$

where $x_{i j}$ is the performance measure of $\mathrm{i}^{\text {th }}$ alternative on $\mathrm{j}^{\text {th }}$ criterion. In MCDM methods, it is also required to determine the priority weight $\left(\mathrm{w}_{\mathrm{j}}\right)$ of each criterion such that the sum of weights for all the criteria equals to one. These priority weights can be determined using AHP or entropy method (Rao, 2007). In SAW method, each alternative is assessed with respect to every criterion. The overall performance score $\left(\mathrm{P}_{\mathrm{i}}\right)$ of $\mathrm{i}^{\text {th }}$ alternative is calculated as follows:

$P_{i}=\sum_{j=1}^{n} w_{j}\left(x_{i j}\right)_{\text {normal }}$

where $\left(\mathrm{x}_{\mathrm{ij}}\right)_{\text {normal }}$ is the normalized value of $x_{i j}$. The alternative having the highest $\mathrm{P}_{\mathrm{i}}$ value is the best choice.

\subsection{Weighted product method}

This method is similar to SAW method. The main difference is that, instead of addition, there is multiplication in this method. The overall performance score $\left(\mathrm{P}_{\mathrm{i}}\right)$ for $\mathrm{i}^{\text {th }}$ alternative is computed as below:

$P_{i}=\prod_{j=1}^{n}\left[\left(x_{i j}\right)_{\text {normal }}\right]^{w_{j}}$.

Here, the normalized value of $i^{\text {th }}$ alternative on $j^{\text {th }}$ criterion is raised to the power of the relative weight of the corresponding criterion. The best alternative is the one having the highest $\mathrm{P}_{\mathrm{i}}$ value.

\subsection{Analytic hierarchy process}

The AHP method (Saaty, 1980) involves a general theory of measurement, which is used to derive ratio scale from both the discrete and continuous paired comparisons in multi-level hierarchical structures. The procedural steps of AHP are as follows: 
Step 1: Define the problem and structure the corresponding hierarchy with a goal/objective at the top level, criteria and sub-criteria at the intermediate levels and alternatives at the lowest level.

Step 2: a) Construct a set of pair-wise comparison matrices for each level in the hierarchy and make all the pair-wise comparisons using the fundamental scale of absolute numbers from 1 to 9 . An element when self-compared is assigned a value of one. Assuming that there are $\mathrm{N}$ number of criteria in a decision-making problem, the pair-wise comparison of $i^{\text {th }}$ criterion with respect to $j^{\text {th }}$ one yields a square matrix, $A_{1}$, where $a_{i j}=1$ when $i=j$ and $a_{j i}=1 / a_{i j}\left(a_{i j}\right.$ is the comparative importance of $i^{\text {th }}$ criterion with respect to $\mathrm{j}^{\text {th }}$ one).

b) Find the relative normalized weight $\left(\mathrm{w}_{\mathrm{j}}\right)$ for each criterion by (i) calculating the geometric mean of $i^{\text {th }}$ row, and (ii) normalizing the geometric mean of rows in the pair-wise comparison matrix. This can be represented by the following equations:

$$
\begin{aligned}
& \mathrm{GM}_{\mathrm{j}}=\left[\prod_{j=1}^{n} a_{i j}\right]^{1 / N} \\
& w_{j}=\mathrm{GM}_{\mathrm{j}} / \sum_{j=1}^{n} \mathrm{GM}_{\mathrm{j}}
\end{aligned}
$$

c) Calculate matrices $A_{3}$ and $A_{4}$ such that $A_{3}=A_{1} \times A_{2}$ and $A_{4}=A_{3} / A_{2}$.

where $\mathrm{A}_{2}=\left[\mathrm{w}_{1}, \mathrm{w}_{2}, \ldots, \mathrm{w}_{\mathrm{N}}\right]^{\mathrm{T}}$.

d) Determine the maximum eigenvalue $\left(\lambda_{\max }\right)$ which is the average of matrix $A_{4}$.

e) Calculate the consistency index (CI) as follows:

$\mathrm{CI}=\left(\lambda_{\max }-\mathrm{N}\right) /(\mathrm{N}-1)$

The smaller is the value of CI, the smaller is the deviation from consistency.

f) Calculate the consistency ratio as $\mathrm{CR}=\mathrm{CI} / \mathrm{RI}$, where $\mathrm{RI}$ is the random index obtained by different orders of the pair-wise comparison matrices. Usually, a CR of 0.1 or less is considered as acceptable which reflects an unbiased judgment of the decision maker.

Step 3: Compare the alternatives pair-wise with respect to how much better they are in satisfying each of the considered criterion.

Step 4: Obtain the overall performance score for an alternative by multiplying the relative normalized weight $\left(\mathrm{w}_{\mathrm{j}}\right)$ of each criterion with its corresponding normalized weight value for each alternative and summing up over all the criteria for the alternative. A ranking of the alternatives is obtained in descending order, depending on the overall performance scores indicating the best and the worst choices for a given problem.

\subsection{TOPSIS method}

This method is based on the concept that the chosen best alternative should have the shortest Euclidean distance from the ideal solution and is the farthest from the negative ideal solution. The main steps involved in TOPSIS method are presented as below:

Step 1: Determine the goal/objective of the problem and identify the pertinent selection criteria.

Step 2: From the original decision matrix, obtain the normalized decision matrix, $\mathrm{D}_{\mathrm{ij}}$ using the following equation: 
$D_{i j}=\frac{x_{i j}}{\sqrt{x_{i 1}^{2} \cdots+x_{i n}^{2}}}$

Step 3: Obtain the weighted normalized matrix, $\mathrm{V}_{\mathrm{ij}}$.

$\mathrm{V}_{\mathrm{ij}}=\mathrm{w}_{\mathrm{j}} \mathrm{D}_{\mathrm{ij}}$,

Step 4: Derive the ideal (best) and the negative ideal (worst) solutions as follows:

$$
\begin{aligned}
& \mathrm{V}^{+}=\left\{\left[\max _{\mathrm{i}} \mathrm{V}_{\mathrm{ij}} / \mathrm{j} \in \mathrm{J}\right],\left[\min _{\mathrm{i}} \mathrm{V}_{\mathrm{ij}} / \mathrm{j} \in \mathrm{J}^{\prime}\right] / \mathrm{i}=1,2, \ldots, \mathrm{m}\right\}=\left(\mathrm{V}_{1}^{+}, \mathrm{V}_{2}^{+}, \mathrm{V}_{3}^{+}, \ldots, \mathrm{V}_{\mathrm{n}}^{+}\right) \\
& \mathrm{V}^{-}=\left\{\left[\min _{\mathrm{i}} \mathrm{V}_{\mathrm{ij}} / \mathrm{j} \in \mathrm{J}\right],\left[\max _{\mathrm{i}} \mathrm{V}_{\mathrm{ij}} / \mathrm{j} \in \mathrm{J}^{\prime}\right] / \mathrm{i}=1,2, \ldots, \mathrm{m}\right\}=\left(\mathrm{V}_{1}^{-}, \mathrm{V}_{2}^{-}, \mathrm{V}_{3}^{-}, \ldots, \mathrm{V}_{\mathrm{n}}^{-}\right)
\end{aligned}
$$

where $J=(j=1,2, \ldots, n) / j$ is associated with beneficial criteria and $J^{\prime}=(j=1,2, \ldots, n) / j$ is associated with non-beneficial criteria.

Step 5: Calculate the separation measures of each alternative from the ideal and the negative ideal solutions using the following equations:

$$
\begin{aligned}
& S_{i}^{+}=\sqrt{\sum_{j=1}^{n}\left(v_{i j}-v_{j}^{+}\right)^{2}}, i=1, \cdots, m \\
& S_{i}^{-}=\sqrt{\sum_{j=1}^{n}\left(v_{i j}-v_{j}^{-}\right)^{2}}, i=1, \cdots, m
\end{aligned}
$$

Step 6: The relative closeness of an alternative to the ideal solution can be expressed as below:

$$
C_{i}=S_{i}^{-} /\left(S_{i}^{+}+S_{i}^{-}\right)
$$

Step 7: Based on the relative closeness measures, the alternatives are ranked in descending order, indicating the best and the worst choices.

\subsection{Graph theory and matrix approach}

Graph theory is a logical and systematic approach for modeling and analyzing different types of systems and problems as encountered in different fields of science and technology. On the other hand, the matrix approach is useful in analyzing the graph/digraph models expeditiously to derive the system functions so as to meet the objectives (Rao, 2007). A digraph usually contains a set of nodes, $\mathrm{N}=\left\{\mathrm{n}_{\mathrm{i}}\right\}$ and a set of directed edges, $\mathrm{D}=\left\{\mathrm{d}_{\mathrm{ij}}\right\}$. A node $\mathrm{n}_{\mathrm{i}}$ represents $\mathrm{i}^{\text {th }}$ criterion and the edges represent the relative importance among the criteria. If $i^{\text {th }}$ criterion is having relative importance over $\mathrm{j}^{\text {th }}$ criterion, a directed edge $\left(\mathrm{d}_{\mathrm{ij}}\right)$ is drawn from $\mathrm{i}^{\text {th }}$ node to $\mathrm{j}^{\text {th }}$ node and vice-versa.

Matrix representation of a digraph gives a one-to-one representation of the entire problem. This is an $\mathrm{NxN}$ matrix and considers all the criteria $\left(\mathrm{X}_{\mathrm{i}}\right)$ and their relative importance $\left(\mathrm{x}_{\mathrm{ij}}\right)$. In general, if there are $\mathrm{N}$ number of criteria and the relative importance exist among them, then the following matrix can be constructed:

$$
B=\left[\begin{array}{cccc}
X_{1} & X_{12} & \cdots & X_{1 N} \\
X_{21} & X_{2} & \cdots & X_{2 N} \\
\cdots & \cdots & \cdots & \cdots \\
X_{N 1} & X_{N 2} & \cdots & X_{N}
\end{array}\right],
$$


where $X_{i}$ is the value of $i^{\text {th }}$ criterion represented by node $n_{i}$ and $x_{i j}$ is the relative importance of $i^{\text {th }}$ criterion over $\mathrm{j}^{\text {th }}$ one represented by edge $\mathrm{d}_{\mathrm{ij}}$. In order to select the best alternative using this approach, the permanent of the above matrix is to be computed. The permanent function is the determinant of a matrix, but considering all the determinant terms as positive ones. If the decision matrix consists of five criteria, the expression for the permanent function can be written as below:

$$
\begin{aligned}
& \operatorname{per}(\mathrm{B})=\prod_{\mathrm{i}=1}^{5} \mathrm{X}_{\mathrm{i}}+\sum_{\mathrm{i}=1}^{4} \sum_{\mathrm{j}=\mathrm{i}+1}^{5} \sum_{\mathrm{k}=11=\mathrm{k}+1}^{2} \sum_{\mathrm{m}=1+1}^{3}\left(\mathrm{x}_{\mathrm{ij}} \mathrm{X}_{\mathrm{ji}}\right) \mathrm{X}_{\mathrm{k}} \mathrm{X}_{\mathrm{l}} \mathrm{X}_{\mathrm{m}}+\sum_{\mathrm{i}=1}^{3} \sum_{\mathrm{j}=\mathrm{i}+1}^{4} \sum_{\mathrm{k}=\mathrm{j}+1}^{5} \sum_{\mathrm{l}=1}^{3} \sum_{\mathrm{m}=1+1}^{4}\left(\mathrm{x}_{\mathrm{ij}} \mathrm{X}_{\mathrm{jk}} \mathrm{X}_{\mathrm{ki}}+\mathrm{X}_{\mathrm{ik}} \mathrm{X}_{\mathrm{kj}} \mathrm{X}_{\mathrm{ji}}\right) \mathrm{X}_{1} \mathrm{X}_{\mathrm{m}} \\
& +\left(\sum_{\mathrm{i}=1}^{2} \sum_{\mathrm{j}=\mathrm{i}+1}^{5} \sum_{\mathrm{k}=\mathrm{j}+1}^{4} \sum_{=\mathrm{i}+2}^{5} \sum_{\mathrm{m}=1+1}^{4}\left(\mathrm{x}_{\mathrm{ij}} \mathrm{X}_{\mathrm{ji}}\right)\left(\mathrm{x}_{\mathrm{kl}} \mathrm{x}_{\mathrm{lk}}\right) \mathrm{X}_{\mathrm{m}}+\sum_{\mathrm{i}=1}^{2} \sum_{\mathrm{j}=\mathrm{i}+1}^{4} \sum_{\mathrm{k}=\mathrm{i}+1}^{5} \sum_{\mathrm{l}=\mathrm{j}+1}^{5} \sum_{\mathrm{m}=1}^{4}\left(\mathrm{x}_{\mathrm{ij}} \mathrm{X}_{\mathrm{jk}} \mathrm{X}_{\mathrm{kl}} \mathrm{x}_{\mathrm{li}}+\mathrm{X}_{\mathrm{il}} \mathrm{x}_{\mathrm{lk}} \mathrm{X}_{\mathrm{kj}} \mathrm{x}_{\mathrm{ji}}\right) \mathrm{X}_{\mathrm{m}}\right)+
\end{aligned}
$$

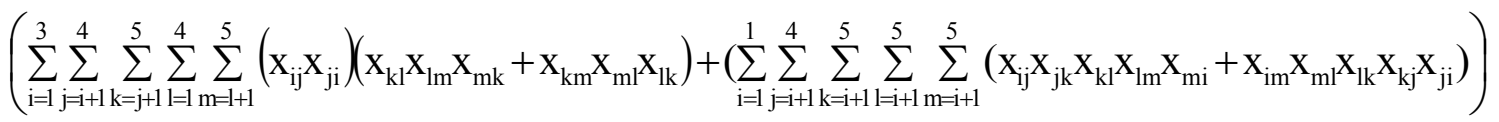

The computational steps of the graph theory and matrix approach are given as below:

Step 1: Identify the pertinent selection criteria for the given problem and shortlist the alternatives on the basis of the identified criteria satisfying the requirements.

Step 2: After shortlisting the alternatives, find out the relative importance $\left(\mathrm{x}_{\mathrm{ij}}\right)$ relation between various criteria and normalize the values of criteria $\left(\mathrm{X}_{\mathrm{i}}\right)$ for different alternatives.

a) Develop the related digraph considering the identified criteria and their relative importance.

b) Construct the decision matrix for the developed digraph. This is an $\mathrm{NxN}$ matrix with diagonal elements of $\mathrm{X}_{\mathrm{i}}$ and off-diagonal elements of $\mathrm{x}_{\mathrm{ij}}$.

c) Obtain the permanent function for the matrix.

d) Substitute $\mathrm{X}_{\mathrm{ij}}$ and $\mathrm{X}_{\mathrm{i}}$ values in the permanent function to evaluate the related indices for the considered alternatives.

e) Arrange the alternatives in descending order based on the selection index values. The alternative having the highest index is the best choice.

\subsection{VIKOR method}

The VIKOR (the Serbian name is 'VIse Kriterijumska Optimizacija kompromisno Resenje' which means multi-criteria optimization and compromise solution) method (Zeleny, 2002, Opricovic \& Tzeng, 2004, 2007) is developed to solve MCDM problems with conflicting and non-commensurate criteria, assuming that compromise can be acceptable for conflict resolution, when the decision maker wants a feasible solution that is the closest to the ideal solution and the alternatives can be evaluated according to all the established criteria. The following multiple attribute merit for compromise ranking is developed from the $\mathrm{L}_{\mathrm{p}}$-metric used in compromise programming method (Rao, 2007).

$$
L_{p, i}=\left\{\sum_{j=1}^{n}\left(w_{j}\left[\left(x_{i j}\right)_{\max }-x_{i j}\right] /\left[\left(x_{i j}\right)_{\max }-\left(x_{i j}\right)_{\min }\right]\right)^{p}\right\}^{1 / p} \quad 1 \leq p \leq \infty ; i=1, \cdots, m
$$

In VIKOR method, $\mathrm{L}_{1, \mathrm{i}}$ and $\mathrm{L}_{\infty, \mathrm{i}}$ are used to formulate the ranking measure. The procedural steps for VIKOR method are as follows:

Step 1: Identify the major selection criteria and shortlist the alternatives.

Step 2: a) From the decision matrix, determine the best, $\left(\mathrm{x}_{\mathrm{ij}}\right)_{\max }$ and the worst, $\left(\mathrm{x}_{\mathrm{ij}}\right)_{\min }$ values of all the criteria.

b) Calculate $E_{i}$ and $F_{i}$ values. 


$$
\begin{aligned}
& E_{i}=L_{1, i}=\sum_{j=1}^{n}\left(w_{j}\left[\left(x_{i j}\right)_{\max }-x_{i j}\right] /\left[\left(x_{i j}\right)_{\max }-\left(x_{i j}\right)_{\min }\right]\right) \quad i=1, \cdots, m \\
& E_{i}=L_{\infty, i}=\max ^{m} \text { of }\left\{\left(w_{j}\left[\left(x_{i j}\right)_{\max }-x_{i j}\right] /\left[\left(x_{i j}\right)_{\max }-\left(x_{i j}\right)_{\min }\right]\right)\right\} j=1, \cdots, n
\end{aligned}
$$

For non-beneficial criteria, Eq. (17) can be rewritten as:

$$
E_{i}=L_{1, i}=\sum_{j=1}^{n}\left(w_{j}\left[x_{i j}-\left(x_{i j}\right)_{\min }\right] /\left[\left(x_{i j}\right)_{\max }-\left(x_{i j}\right)_{\min }\right]\right) \quad i=1, \cdots, m
$$

c) Calculate $P_{i}$ value

$\mathrm{P}_{\mathrm{i}}=v\left(\left(\mathrm{E}_{\mathrm{i}}-\mathrm{E}_{\mathrm{i}-\mathrm{min}}\right) /\left(\mathrm{E}_{\mathrm{i}-\mathrm{max}}-\mathrm{E}_{\mathrm{i}-\min }\right)\right)+(1-v)\left(\left(\mathrm{F}_{\mathrm{i}}-\mathrm{F}_{\mathrm{i}-\min }\right) /\left(\mathrm{F}_{\mathrm{i}-\max }-\mathrm{F}_{\mathrm{i}-\min }\right)\right)$

where $\mathrm{E}_{\mathrm{i}-\mathrm{max}}$ and $\mathrm{E}_{\mathrm{i}-\min }$ are the maximum and minimum values of $\mathrm{E}_{\mathrm{i}}$ respectively, and $\mathrm{F}_{\mathrm{i}-\mathrm{max}}$ and $\mathrm{F}_{\mathrm{i}-\min }$ are the maximum and minimum values of $\mathrm{F}_{\mathrm{i}}$ respectively. $v$ is introduced as weight of the strategy of 'the majority of attributes' (or 'the maximum group utility'). The value of $v$ lies in the range of 0 to 1 . Normally, its value is taken as 0.5 .

d) Arrange the alternatives in ascending order, according to $P_{i}$ values. The best alternative is the one having the minimum $\mathrm{P}_{\mathrm{i}}$ value.

\subsection{ELECTRE II method}

The ELECTRE method (Roy \& Vincke, 1981) is based on multi-attribute utility theory with the intention to improve efficiency without affecting the outcome while considering less information. It is a procedure that sequentially reduces the number of alternatives the decision maker is faced within a set of non-dominated alternatives. The aim of this outranking method is to find all alternatives that dominate other alternatives while they cannot be dominated by any other alternative. In ELECTRE method, every pair of the alternatives $A_{i}$ and $A_{k}$ is assigned a concordance index, $c(i, k)$ which can be expressed as below:

$$
c(i, k)=\sum_{g_{j}(i) \geq g_{j}(k)} w_{j}, \quad i, k=1, \cdots, m, i \neq k
$$

where $g_{j}(i)$ and $g_{j}(k)$ are the normalized measures of performance of $i^{\text {th }}$ and $k^{\text {th }}$ alternative respectively with respect to $j^{\text {th }}$ criterion. Thus, for an ordered pair of alternatives $\left(A_{i}, A_{k}\right)$, the concordance index, $c(i, k)$ is the sum of all the weights for those criteria where the performance score of $A_{i}$ is at least as that of $A_{k}$. A discordance index, $d(i, k)$ is also calculated as given below:

$$
d(i, k)=\left\{\begin{array}{cl}
0 & \text { if } g_{j}(k) \geq g_{j}(k), \quad j=1, \cdots, n \\
\frac{\max _{g_{j}(k)>g_{j(i)}}\left(g_{j}(k)-g_{j}(i)\right)}{\max _{j=1, \cdots, n}\left(g_{j}(k)-g_{j}(i)\right)} & \text { otherwise } \quad i, k=1, \cdots m, i \neq k
\end{array}\right.
$$

Once these two indices are determined, an outranking relation $\mathrm{S}$ can be defined as:

$$
A_{i} S A_{k} \text { if and only if } c(i, k) \geq \hat{c} \text { and } d(i, k) \leq \hat{d}
$$

where $\hat{c}$ and $\hat{\mathrm{d}}$ are the threshold values as set by the decision maker. For an outranking relation to be judged as true, both the concordance and discordance indices should not violate their corresponding threshold values. The steps for ELECTRE method are described as below:

Step 1: Obtain the normalized values of all the criteria. 
Step 2: Construct the outranking relations by following the concordance and discordance definitions, and develop a graph representing the dominance relations among the alternatives. In this graph, if alternative $A_{i}$ outranks alternative $A_{k}$, then a directed arc exists from $A_{i}$ to $A_{k}$.

Step 3: Obtain a minimum dominating subset by using the minimum concordance and maximum discordance indices.

Step 4: If the subset has a single element or is small enough to apply value judgment, select the final decision. Otherwise, steps (2)-(4) are repeated until a single element or small subset exists.

Step 5: If a full ranking of the alternatives is required, apply an extension of ELECTRE (ELECTRE II) method.

Calculate another two indices as follows:

Pure concordance index $\left(C_{i}\right)=\sum_{k=1}^{m} c(i, k)-\sum_{i=1}^{m} c(k, i) \quad(\mathrm{i} \neq \mathrm{k})$

Pure concordance index $\left(D_{i}\right)=\sum_{k=1}^{m} d(i, k)-\sum_{i=1}^{m} d(k, i) \quad(\mathrm{i} \neq \mathrm{k})$

a) Once these two indices are estimated, obtain two rankings on the basis of these indices.

b) Determine an average ranking from the two rankings, as obtained in step 5(a).

c) Select that alternative which has the best average rank.

\subsection{PROMETHEE II method}

Preference function based outranking method is an MCDM approach that can provide a ranking ordering of the decision options (Rao \& Patel, 2009, Behzadian et al., 2010). PROMETHEE I method can provide the partial ordering of the alternatives, whereas, PROMETHEE II method can derive the full ranking of the alternatives by using a net flow, though it loses much information of preference relations. The procedural steps of PROMETHEE II method are enlisted as below:

Step 1: Normalize the decision matrix.

Step 2: Calculate the evaluative differences of $\mathrm{i}^{\text {th }}$ alternative with respect to other alternatives. This step involves pair-wise calculation of differences in criteria values between different alternatives.

Step 3: Calculate the preference function, $P_{j}\left(i, i^{\prime}\right)$

There are mainly six types of generalized preference functions, e.g. usual criterion, U-shape criterion, V-shaped criterion, level criterion, V-shape with indifference criterion and Gaussian criterion. But these preference functions require the definition of some preferential parameters, such as preference and indifference thresholds. However, in real time applications, it may be difficult for the decision maker to specify which specific form of preference function is suitable for each criterion. To avoid this problem, the following simplified preference function is used here:

$$
\begin{array}{lll}
P_{j}\left(i, i^{\prime}\right)=0 & \text { if } \quad R_{i j} \leq R_{i^{\prime} j} \\
P_{j}\left(i, i^{\prime}\right)=\left(R_{i j}-R_{i^{\prime} j}\right) & \text { if } \quad R_{i j}>R_{i^{\prime} j}
\end{array}
$$

where $R_{i j}$ is the performance of $i^{\text {th }}$ alternative on $j^{\text {th }}$ criterion in the normalized decision matrix.

Step 4: Calculate the aggregated preference function, $P_{j}\left(i, i^{\prime}\right)$ considering the criteria weights. 


$$
\pi\left(i, i^{\prime}\right)=\left[\sum_{i=1}^{n} w_{j} P_{j}\left(i, i^{\prime}\right)\right] / \sum_{i=1}^{n} w_{j}
$$

Step 5: Determine the leaving and the entering outranking flows as follows:

Leaving (positive) flow for $\mathrm{i}^{\text {th }}$ alternative, $\varphi^{+}(i)=\frac{1}{m-1} \sum_{i^{\prime}=1}^{m} \pi\left(i, i^{\prime}\right) \quad\left(i \neq i^{\prime}\right)$

Entering (negative) flow for $\mathrm{i}^{\text {th }}$ alternative, $\varphi^{-}(i)=\frac{1}{m-1} \sum_{i^{\prime}=1}^{m} \pi\left(i^{\prime}, i\right) \quad\left(i \neq i^{\prime}\right)$

The leaving flow expresses how much an alternative dominates the other alternatives, while the entering flow denotes how much an alternative is dominated by the other alternatives.

Step 6: Calculate the net outranking flow for each alternative.

$\varphi(\mathrm{i})=\varphi^{+}(\mathrm{i})-\varphi^{-}(\mathrm{i})$

Step 7: Determine the rankings of all the considered alternatives depending on the values of $\varphi(i)$. Thus, the best alternative is the one having the highest $\varphi(i)$ value.

\subsection{Grey relational analysis}

The initial step of GRA method is to translate the performance of all the alternatives into a comparability sequence. According to these sequences, a reference sequence (ideal target sequence) is defined. Then, the grey relational coefficient between all the comparability sequences and the reference sequence are calculated. Finally, based on these grey relational coefficients, the grey relational grade (GRG) between the reference sequence and each comparability sequence is computed. If a comparability sequence translated from an alternative has the highest GRG between the reference sequence and itself, that alternative will be the best choice. The procedural steps of GRA method are described as follows:

Step 1: Generate the grey relation using an appropriate normalization procedure.

Step 2: Define the reference sequence.

For $\mathrm{j}^{\text {th }}$ criterion of $\mathrm{i}^{\text {th }}$ alternative, if the value $\mathrm{x}_{\mathrm{ij}}$ is equal to 1 , or nearer to 1 than the value of the other alternatives, the performance of $i^{\text {th }}$ alternative is the best one for that $\mathrm{j}^{\text {th }}$ criterion. Therefore, an alternative will be the best choice if all of its performance values are closest to or equal to 1 . The reference alternative is defined as $\mathrm{x}_{0}$.

Step 3: Calculate the grey relational coefficient.

Grey relational coefficient is used to determine how close $x_{i j}$ is to $x_{0 j}$. The larger the grey relational coefficient, the closer $\mathrm{x}_{\mathrm{ij}}$ and $\mathrm{x}_{0 \mathrm{j}}$ are. It is calculated using the following equation:

$\gamma\left(\mathrm{x}_{0 \mathrm{j}}, \mathrm{x}_{\mathrm{ij}}\right)=\left(\Delta_{\min }+\zeta \Delta_{\max }\right) /\left(\Delta_{\mathrm{ij}}+\zeta \Delta_{\max }\right)$

where $\gamma\left(\mathrm{x}_{0 \mathrm{j}}, \mathrm{x}_{\mathrm{ij}}\right)$ is the grey relational coefficient between $\mathrm{x}_{\mathrm{ij}}$ and $\mathrm{x}_{0 \mathrm{j}}, \Delta_{\mathrm{ij}}=\left|\mathrm{x}_{0 \mathrm{j}}-\mathrm{x}_{\mathrm{ij}}\right|, \Delta_{\min }$ is the minimum value of $\Delta_{\mathrm{ij}}$ and $\Delta_{\max }$ is the maximum value of $\Delta_{\mathrm{ij}} . \zeta$ is the distinguishing coefficient which ranges from 0 to 1 and generally, is taken as 0.5 .

Step 4 Compute the GRG value as follows:

GRG between $x_{i}$ and $x_{0}=\sum_{j=1}^{n} w_{j} \gamma\left(x_{0 j}, x_{i j}\right)$ 
The GRG represents the level of correlation between the reference sequence and the comparability sequence. If the comparability sequence for an alternative gets the highest GRG value with the reference sequence, it means that the comparability sequence is most similar to the reference sequence and that alternative is the best choice.

\subsection{Range of value method}

The range of value method calculates the best and the worst utility for each alternative. This is achieved by maximizing and minimizing a utility function. For a linear additive model, the best utility $\left(\mathrm{u}_{\mathrm{i}}^{+}\right)$and the worst utility $\left(\mathrm{u}_{\mathrm{i}}^{-}\right)$for $\mathrm{i}^{\text {th }}$ alternative are obtained using the following equations:

$$
\begin{aligned}
& \max u_{i}^{+}=\sum_{j=1}^{n} v_{i j} w_{j} \\
& \min u_{i}^{-}=\sum_{j=1}^{n} v_{i j} w_{j}
\end{aligned}
$$

If $\mathrm{u}_{\mathrm{i}}^{-}>\mathrm{u}_{\mathrm{i}}^{+}$then alternative $\mathrm{i}$ outperforms alternative $\mathrm{k}$ regardless of the actual quantitative weights. If it is not possible to differentiate the alternatives on this basis, then a scoring (enabling subsequent ranking) can be attained from the midpoint, which can be calculated as below:

$$
\mathrm{u}_{\mathrm{i}}=\frac{\mathrm{u}_{\mathrm{i}}^{-}+\mathrm{u}_{\mathrm{i}}^{+}}{2}
$$

The alternative having the highest $\mathrm{u}_{\mathrm{i}}$ value is the best choice.

\section{Illustrative Example}

This example (Bhangale et al., 2004) deals with the selection of the most appropriate industrial robot for some pick-n-place operations where it has to avoid certain obstacles. Performance of an industrial robot is often specified using different attributes. Repeatability, accuracy, load capacity, memory capacity, manipulator reach and velocity are observed to be the most critical attributes affecting the robot selection decision. Repeatability is the measure of the ability of a robot to return to the same position and orientation over and over again, while accuracy is the measure of closeness between the robot end effectors and the target point, and can usually be defined as the distance between the target point and the center of all points to which the robot goes on repeated trials. It is easier to correct poor accuracy than repeatability and thus, repeatability is generally assumed to be a more important attribute. Load capacity is the maximum load that a manipulator can carry without affecting its performance. Maximum tip speed is the speed at which a robot can move in an inertial reference frame. Memory capacity of a robot is measured in terms of number of points or steps that it can store in its memory while traversing along a predefined path. Manipulator reach is the maximum distance that can be covered by the robotic manipulator so as to grasp objects for the given pick-n-place operation. In this example (Bhangale et al., 2004), five different robot selection attributes are considered as load capacity (LC), repeatability (RE), maximum tip speed (MTS), memory capacity (MC) and manipulator reach (MR), among which load capacity, maximum tip speed, memory capacity and manipulator reach are beneficial attributes (where higher values are desirable), whereas, repeatability is a non-beneficial attribute (where lower value is preferable). Thus, the industrial robot selection problem consists of five criteria and seven alternative robots, as shown in Table 1. Bhangale et al. (2004) estimated the criteria weights as $\mathrm{w}_{\mathrm{LC}}=0.1761, \mathrm{w}_{\mathrm{RE}}=0.2042, \mathrm{w}_{\mathrm{MTS}}=0.2668, \mathrm{w}_{\mathrm{MC}}=$ 0.2430 and $\mathrm{w}_{\mathrm{MR}}=0.2286$ using AHP method. But the sum of these criteria weights exceeds one. Hence, these are re-normalized as $\mathrm{w}_{\mathrm{LC}}=0.1574, \mathrm{w}_{\mathrm{RE}}=0.1825, \mathrm{w}_{\mathrm{MTS}}=0.2385, \mathrm{w}_{\mathrm{MC}}=0.2172$ and $\mathrm{w}_{\mathrm{MR}}=0.2043$, and used for subsequent analyses. 
Table 1

Quantitative data for robot selection (Bhangale et al., 2004)

\begin{tabular}{lllllll}
\hline $\begin{array}{l}\text { S1. } \\
\text { No. }\end{array}$ & Robot & $\begin{array}{l}\text { Load capacity } \\
(\mathrm{kg})\end{array}$ & $\begin{array}{l}\text { Repeatability } \\
(\mathrm{mm})\end{array}$ & $\begin{array}{l}\text { Maximum tip } \\
\text { speed }(\mathrm{mm} / \mathrm{s})\end{array}$ & $\begin{array}{l}\text { Memory } \\
\text { capacity }\end{array}$ & $\begin{array}{l}\text { Manipulator } \\
\text { reach }(\mathrm{mm})\end{array}$ \\
\hline 1. & ASEA-IRB 60/2 & 60 & 0.40 & 2540 & 500 & 990 \\
2. & Cincinnati Milacrone T3-726 & 6.35 & 0.15 & 1016 & 3000 & 1041 \\
3. & Cybotech V15 Electric Robot & 6.8 & 0.10 & 1727.2 & 1500 & 1676 \\
4. & Hitachi America Process Robot & 10 & 0.20 & 1000 & 2000 & 965 \\
5. & Unimation PUMA 500/600 & 2.5 & 0.10 & 560 & 500 & 915 \\
6. & United States Robots Maker 110 & 4.5 & 0.08 & 1016 & 350 & 508 \\
7. & Yaskawa Electric Motoman L3C & 3 & 0.10 & 177 & 1000 & 920 \\
\hline
\end{tabular}

\subsection{Simple additive weighting method}

In this method, the performance scores for all the alternative robots are calculated using Eq. (2), as shown in Table 2. Based on the descending values of the performance score, the alternatives are arranged as 2-3-1-5-7-6-4 which reveals that Cybotech V15 Electric Robot is the best choice followed by ASEA-IRB 60/2 robot. Robot 5 (Unimation PUMA 500/600) is the worst choice.

Table 2

Performance scores using SAW method

\begin{tabular}{llllllll}
\hline Robot & 1 & 2 & 3 & 4 & 5 & 6 & 7 \\
\hline $\mathrm{P}_{\mathrm{i}}$ & 0.5893 & 0.5535 & 0.6390 & 0.4556 & 0.3529 & 0.3770 & 0.5054 \\
\hline
\end{tabular}

\subsection{Weighted product method}

Using Eq. (3), the performance scores of the alternative robots are calculated, as given in Table 3. When arranged in descending order according to the values of the performance score, the ranking of the alternatives is obtained as 2-3-1-4-7-6-5 which suggests that Cybotech V15 Electric Robot and ASEA-IRB 60/2 are the first and second best choices.

Table 3

Performance scores using WPM

\begin{tabular}{llllllll}
\hline Robot & 1 & 2 & 3 & 4 & 5 & 6 & 7 \\
\hline $\mathrm{P}_{\mathrm{i}}$ & 4.3210 & 4.3048 & 4.4422 & 4.2099 & 3.8250 & 3.8795 & 4.1749 \\
\hline
\end{tabular}

\subsection{Analytic hierarchy process}

At first, in this method, all the alternative robots are pair-wise compared with respect to all the selection criteria using Saaty's 1-9 absolute scale of measurement. Table 4 shows such a pair-wise comparison matrix when all the considered alternatives are pair-wise compared with respect to 'load capacity' criterion.

\section{Table 4}

Pair-wise comparison matrix of the alternatives with respect to 'load capacity' criterion

\begin{tabular}{lllllllll}
\hline Robot & 1 & 2 & 3 & 4 & 5 & 6 & 7 & PW \\
\hline 1 & 1 & 2 & 1 & 2 & 3 & 4 & 2 & 0.2542 \\
2 & $1 / 2$ & 1 & 1 & $1 / 2$ & 3 & 1 & 1 & 0.1271 \\
3 & 1 & 1 & 1 & 3 & 2 & 2 & 1 & 0.1888 \\
4 & $1 / 2$ & 2 & $1 / 3$ & 1 & $1 / 2$ & $1 / 3$ & 1 & 0.0876 \\
5 & $1 / 3$ & $1 / 3$ & $1 / 2$ & 2 & 1 & $1 / 2$ & $1 / 3$ & 0.0749 \\
6 & $1 / 4$ & 1 & $1 / 2$ & 3 & 2 & 1 & 1 & 0.1271 \\
7 & $1 / 2$ & 1 & 1 & 1 & 3 & 1 & 1 & 0.1403 \\
\hline
\end{tabular}


The last column of this table gives the priority weights (PW) as calculated using the steps shown in sub-section 3.3. Likewise, another four sets of priority weights are also obtained when the alternative robots are pair-wise compared with respect to the remaining four criteria, i.e. repeatability, maximum tip speed, memory capacity and manipulator reach. Now, these normalized priority weights of the alternative robots with respect to different criteria and the criteria weights are multiplied to yield the performance scores for the robots. The detailed calculations are given below.

$\left[\begin{array}{lllll}0.2542 & 0.1159 & 0.1145 & 0.1332 & 0.1179 \\ 0.1271 & 0.1497 & 0.1396 & 0.2098 & 0.1681 \\ 0.1888 & 0.2647 & 0.2110 & 0.2098 & 0.2301 \\ 0.0876 & 0.1413 & 0.1396 & 0.2098 & 0.1379 \\ 0.0749 & 0.1007 & 0.1265 & 0.0723 & 0.1323 \\ 0.1271 & 0.1228 & 0.1081 & 0.0846 & 0.1112 \\ 0.1403 & 0.1050 & 0.1606 & 0.1624 & 0.1025\end{array}\right]\left[\begin{array}{lllll}0.1574 & 0.1825 & 0.2385 & 0.2172 & 0.2043\end{array}\right]=\left[\begin{array}{l}0.1415 \\ 0.1605 \\ 0.2209 \\ 0.1288 \\ 0.1031 \\ 0.1093 \\ 0.1358\end{array}\right]$

After arranging these scores in descending order, the ranking of the robots is obtained as 3-2-1-5-7-64, indicating that Cybotech V15 Electric Robot is the best choice for the given application.

\subsection{TOPSIS method}

In this method, from the normalized decision matrix, the corresponding weighted normalized decision matrix is obtained, applying Eq. (8) and is shown in Table 5. Now, using Eq. (9) and Eq. (10), the ideal and the negative ideal solutions are respectively computed, as given in Table 6 . Then applying Eq. (11) and Eq. (12), the separation measures of each alternative robot from the ideal and the negative ideal solutions are estimated, as shown in Table 7. Finally, the relative closeness values of all the candidate robots with respect to the ideal solution are computed and are shown in Table 8, which results in a ranking of robots as 1-3-2-5-7-6-4. This reveals that ASEA-IRB 60/2 is the best robot, followed by Cybotech V15 Electric Robot.

Table 5

Weighted normalized decision matrix

\begin{tabular}{llllll}
\hline Robot & LC & RE & MTS & MC & MR \\
\hline 1 & 0.1528 & 0.1435 & 0.1516 & 0.0264 & 0.0727 \\
2 & 0.0162 & 0.0538 & 0.0606 & 0.1586 & 0.0764 \\
3 & 0.0173 & 0.0359 & 0.1031 & 0.0793 & 0.1231 \\
4 & 0.0255 & 0.0717 & 0.0597 & 0.1058 & 0.0709 \\
5 & 0.0064 & 0.0359 & 0.0334 & 0.0264 & 0.0672 \\
6 & 0.0115 & 0.0287 & 0.0606 & 0.0185 & 0.0373 \\
7 & 0.0076 & 0.0359 & 0.1061 & 0.0529 & 0.0675 \\
\hline
\end{tabular}

Table 6

Ideal and negative ideal solutions

\begin{tabular}{llllll}
\hline $\mathrm{V}^{+}$ & 0.1528 & 0.0287 & 0.1516 & 0.1586 & 0.1231 \\
\hline $\mathrm{V}^{-}$ & 0.0064 & 0.1435 & 0.0334 & 0.0185 & 0.0373 \\
\hline
\end{tabular}


Table 7

Separation measures

\begin{tabular}{llllllll}
\hline Robot & 1 & 2 & 3 & 4 & 5 & 6 & 7 \\
\hline $\mathrm{S}_{\mathrm{i}}^{+}$ & 0.1822 & 0.1724 & 0.1645 & 0.1790 & 0.2367 & 0.2350 & 0.1935 \\
$\mathrm{~S}_{\mathrm{i}}^{-}$ & 0.1916 & 0.1733 & 0.1661 & 0.1222 & 0.1120 & 0.1181 & 0.1377 \\
\hline
\end{tabular}

Table 8

Relative closeness values

\begin{tabular}{llllllll}
\hline Robot & 1 & 2 & 3 & 4 & 5 & 6 & 7 \\
\hline $\mathrm{C}_{\mathrm{i}}$ & 0.5126 & 0.5013 & 0.5026 & 0.4058 & 0.3211 & 0.3344 & 0.4157 \\
\hline
\end{tabular}

\subsection{Graph theory and matrix approach}

Based on the five robot selection criteria, the corresponding robot selection digraph is developed, as shown in Fig. 1. This digraph gives a graphical representation of the considered criteria and their relative importance for quick visual appraisal. Using an 11-point scale, as proposed by Rao (2007), the matrix of Table 9 is developed which shows the relative importance between different criteria. The numerical value of the robot selection criteria function or the permanent function is called the robot selection index (RSI) which is a measure of degree or extent by which a robot can be successfully selected. The robot selection indices for different alternatives are calculated by solving the permanent function, as given in Eq. (15), while substituting the values of $\mathrm{X}_{\mathrm{i}}$ and $\mathrm{x}_{\mathrm{ij}}$. The robot with the highest RSI value is the best choice.

Table 10 shows the RSI values for the alternative robots, which gives a ranking as 2-3-1-5-7-6-4 showing that Cybotech V15 Electric Robot and ASEA-IRB 60/2 are the first and second best choices.

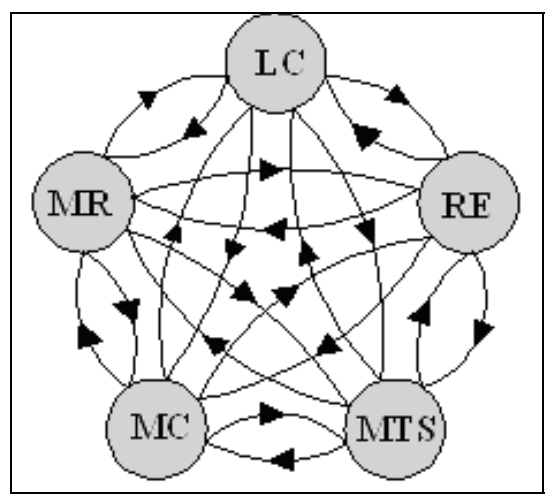

Fig. 1. Developed digraph

Table 9

Relative importance between different criteria

\begin{tabular}{llllll}
\hline Criteria & LC & RE & MTS & MC & MR \\
\hline LC & - & 0.590 & 0.665 & 0.590 & 0.745 \\
RE & 0.410 & - & 0.590 & 0.410 & 0.745 \\
MTS & 0.335 & 0.410 & - & 0.335 & 0.865 \\
MC & 0.410 & 0.590 & 0.665 & - & 0.865 \\
MR & 0.255 & 0.255 & 0.135 & 0.135 & - \\
\hline
\end{tabular}


Table 10

Robot selection indices

\begin{tabular}{llllllll}
\hline Robot & 1 & 2 & 3 & 4 & 5 & 6 & 7 \\
\hline RSI & 2.8790 & 2.6802 & 3.2780 & 2.2558 & 1.8092 & 1.8151 & 2.4108 \\
\hline
\end{tabular}

\subsection{VIKOR method}

For solving this problem using VIKOR method, at first, the best and the worst values of all the criteria are identified. Now, the values of $E_{i}$ and $F_{i}$ are calculated using Eqns. (17) or (19) and (18) respectively, as given in Table 11. Table 11 also shows the $\mathrm{P}_{\mathrm{i}}$ values (for $v=0.5$ ) which when arranged in ascending order, gives a relative ranking of robots as 4-3-1-5-7-6-2. The best choice of robot for the given pick-n-place operation is robot 3 (Cybotech V15 Electric Robot). Yaskawa Electric Motoman L3C is the second choice and the last choice is robot 5 (Unimation PUMA $500 / 600)$.

\section{Table 11}

$\mathrm{E}_{\mathrm{i}}, \mathrm{F}_{\mathrm{i}}$ and $\mathrm{P}_{\mathrm{i}}$ values

\begin{tabular}{llllllll}
\hline Robot & 1 & 2 & 3 & 4 & 5 & 6 & 7 \\
\hline $\mathrm{E}_{\mathrm{i}}$ & 0.5075 & 0.4815 & 0.3779 & 0.5972 & 0.7454 & 0.7571 & 0.5554 \\
$\mathrm{~F}_{\mathrm{i}}$ & 0.2049 & 0.1836 & 0.1456 & 0.1855 & 0.2385 & 0.2172 & 0.1639 \\
$\mathrm{P}_{\mathrm{i}}$ & 0.4901 & 0.3408 & 0 & 0.5038 & 0.9846 & 0.8854 & 0.3326 \\
\hline
\end{tabular}

\subsection{ELECTRE II method}

To solve this problem using ELECTRE II method, the original decision matrix is first normalized. Then, using Eqns. (21) and (22), the concordance and discordance indices are calculated, as shown in Table 12 and 13 respectively. In order to obtain the full ranking of the alternative robots, the corresponding pure concordance and discordance indices are also computed, as given in Table 14 . The final ranking is obtained as 2-3-1-6-7-5-4. Cybotech V15 Electric Robot and ASEA-IRB 60/2 obtain the first and second ranks respectively.

Table 12

Concordance matrix

\begin{tabular}{llllllll}
\hline Robot & 1 & 2 & 3 & 4 & 5 & 6 & 7 \\
\hline 1 & - & 0.3959 & 0.3959 & 0.6002 & 0.7088 & 0.8174 & 0.6002 \\
2 & 0.6041 & - & 0.2172 & 0.8426 & 0.8175 & 0.6982 & 0.5790 \\
3 & 0.6041 & 0.7828 & - & 0.6254 & 0.9087 & 0.8175 & 0.6702 \\
4 & 0.3997 & 0.1574 & 0.3746 & - & 0.8175 & 0.5790 & 0.5790 \\
5 & 0.2911 & 0.1825 & 0.0913 & 0.1825 & - & 0.4216 & 0.0913 \\
6 & 0.1825 & 0.3018 & 0.1825 & 0.4210 & 0.5784 & - & 0.3399 \\
7 & 0.3997 & 0.4210 & 0.3298 & 0.4210 & 0.9087 & 0.6601 & - \\
\hline
\end{tabular}

Table 13

Discordance matrix

\begin{tabular}{llllllll}
\hline Robot & 1 & 2 & 3 & 4 & 5 & 6 & 7 \\
\hline 1 & - & 0.9678 & 0.3904 & 0.6229 & 0 & 0 & 0.1819 \\
2 & 1.0000 & - & 0.3847 & 0 & 0 & 0 & 1.0000 \\
3 & 1.0000 & 1.0000 & - & 0 & 0 & 1.0000 & 0 \\
4 & 0.6581 & 0 & 0 & - & - & 1.0000 & 1.0000 \\
5 & 0 & 1.0000 & 0.3150 & 0 & 1.0000 & - & 0.5556 \\
6 & 0 & 0.5984 & 1.0000 & 0.2500 & 1.0000 & 1.0000 \\
7 & 0.1444 & 0 & 0.6618 & 0.4500 & 1.0000 & - \\
\hline
\end{tabular}


Table 14

Ranking of robots using ELECTRE II method

\begin{tabular}{|c|c|c|c|c|c|c|c|}
\hline Robot & $\begin{array}{l}\text { Pure } \\
\text { index }\end{array}$ & concordance & $\begin{array}{l}\text { Initial } \\
\text { rank }\end{array}$ & $\begin{array}{l}\text { Pure discordance } \\
\text { index }\end{array}$ & $\begin{array}{l}\text { Initial } \\
\text { rank }\end{array}$ & $\begin{array}{l}\text { Average } \\
\text { rank }\end{array}$ & $\begin{array}{l}\text { Final } \\
\text { rank }\end{array}$ \\
\hline 1 & 1.0373 & & 3 & -0.6396 & 2 & 2.5 & 2 \\
\hline 2 & 1.5171 & & 2 & -0.1815 & 4 & 3 & 3 \\
\hline 3 & 2.8174 & & 1 & -0.7518 & 1 & 1 & 1 \\
\hline 4 & -0.1856 & & 5 & 1.3352 & 7 & 6 & 6 \\
\hline 5 & -3.4794 & & 7 & 0.8705 & 6 & 6.5 & 7 \\
\hline 6 & -1.9875 & & 6 & -0.1516 & 5 & 5.5 & 5 \\
\hline 7 & 0.2807 & & 4 & -0.4812 & 3 & 3.5 & 4 \\
\hline
\end{tabular}

\subsection{PROMETHEE II method}

In this method, at first, using Eqs. (26) or (27), the preference functions are calculated for all the pairs of alternatives. Table 15 shows the aggregated preference function values for all the paired alternatives, computed using Eq. (28). Now, the leaving and the entering flows for different alternative robots are estimated, using Eqns. (29) and (30) respectively, and are given in Table 16. Based on these leaving and entering flows, the net outranking flow values for the alternative robots are then determined, as given in Table 17. The alternatives are now ranked in descending order according to the net outranking flow value, which results in a comparative ranking of robots as 3-2-15-6-7-4. Here, Cybotech V15 Electric Robot and Cincinnati Milacrone T3-726 are the first and second best choices.

Table 15

Aggregated preference function values

\begin{tabular}{llllllll}
\hline Robot & 1 & 2 & 3 & 4 & 5 & 6 & 7 \\
\hline 1 & - & 0.3304 & 0.2435 & 0.3267 & 0.4090 & 0.4321 & 0.2601 \\
2 & 0.3564 & - & 0.1230 & 0.1257 & 0.3662 & 0.3155 & 0.1943 \\
3 & 0.3731 & 0.2265 & - & 0.2690 & 0.3675 & 0.3906 & 0.1837 \\
4 & 0.2370 & 0.0100 & 0.0497 & - & 0.2052 & 0.2303 & 0.1090 \\
5 & 0.1711 & 0.0285 & 0 & 0.0570 & - & 0.0835 & 0 \\
6 & 0.1825 & 0.0399 & 0.0114 & 0.0704 & 0.0718 & - & 0.0155 \\
7 & 0.2121 & 0.1203 & 0.0061 & 0.1508 & 0.1899 & 0.2171 & - \\
\hline
\end{tabular}

Table 16

Leaving and entering flows

\begin{tabular}{llllllll}
\hline Robot & 1 & 2 & 3 & 4 & 5 & 6 & 7 \\
\hline$\phi^{+}(\mathrm{i})$ & 0.3337 & 0.2469 & 0.3017 & 0.1402 & 0.0567 & 0.0653 & 0.1494 \\
$\phi^{-}(\mathrm{i})$ & 0.25539 & 0.12595 & 0.07229 & 0.16661 & 0.26828 & 0.27819 & 0.12709 \\
\hline
\end{tabular}

Table 17

Net outranking flow values

\begin{tabular}{llllllll}
\hline Robot & 1 & 2 & 3 & 4 & 5 & 6 & 7 \\
\hline $\begin{array}{l}\text { Net outranking } \\
\text { flow }\end{array}$ & 0.0783 & 0.1209 & 0.2294 & -0.0264 & -0.2116 & -0.2129 & 0.0223 \\
\hline
\end{tabular}

4.9 Grey relational analysis

In this method, after normalizing the original decision matrix, the grey relational coefficients are calculated using Eq. (32), where the value of the distinguishing coefficient $(\zeta)$ is taken as 0.5. Table 
18 shows the grey relational coefficients for all the alternative robots with respect to five different selection criteria. Now, the corresponding GRG values are determined, as shown in Table 19. After arranging the GRG values in descending order, the ranking of the alternative robots is obtained as 23-1-5-7-6-4. Cybotech V15 Electric Robot is the best choice followed by ASEA-IRB 60/2.

Table 18

Grey relational coefficients

\begin{tabular}{llllll}
\hline Robot & LC & RE & MTS & MC & MR \\
\hline 1 & 1.0000 & 0.3333 & 1.0000 & 0.3464 & 0.4598 \\
2 & 0.3489 & 0.6957 & 0.3938 & 1.0000 & 0.4791 \\
3 & 0.3508 & 0.8889 & 0.5491 & 0.4690 & 1.0000 \\
4 & 0.3651 & 0.5714 & 0.3913 & 0.5699 & 0.4510 \\
5 & 0.3333 & 0.8889 & 0.3333 & 0.3464 & 0.4342 \\
6 & 0.3412 & 1.0000 & 0.3938 & 0.3333 & 0.3333 \\
7 & 0.3353 & 0.8889 & 0.5651 & 0.3985 & 0.4358 \\
\hline
\end{tabular}

Table 19

Grey relation grades

\begin{tabular}{llllllll}
\hline Robot & 1 & 2 & 3 & 4 & 5 & 6 & 7 \\
\hline GRG & 0.6260 & 0.5909 & 0.6547 & 0.4710 & 0.4582 & 0.4707 & 0.5254 \\
\hline
\end{tabular}

\subsection{Range of value method}

Here, the best and the worst utility functions for each alternative robot are calculated applying Eqns. (34) and (35) respectively. These are shown in Table 20, where the midpoints of the best and the worst utility functions are also determined to obtain the comparative ranking of the alternatives as 32-1-5-6-7-4, when sorted in descending order. It reveals that Cybotech V15 Electric Robot and Cincinnati Milacrone T3-726 are the first and second choices respectively.

Table 20

Best and worst utility functions

\begin{tabular}{llll}
\hline Robot & $\mathrm{u}_{\mathrm{i}}^{+}$ & $\mathrm{u}_{\mathrm{i}}^{-}$ & $\mathrm{u}_{\mathrm{i}}$ \\
\hline 1 & 0.4925 & 0.0000 & 0.2463 \\
2 & 0.3759 & 0.1426 & 0.2593 \\
3 & 0.4510 & 0.1711 & 0.3110 \\
4 & 0.2887 & 0.1141 & 0.2014 \\
5 & 0.0835 & 0.1711 & 0.1273 \\
6 & 0.0604 & 0.1825 & 0.1215 \\
7 & 0.2734 & 0.1711 & 0.2223 \\
\hline
\end{tabular}

\section{Comparative Analysis}

To determine the applicability and suitability of the ten above-cited MCDM methods to solve this industrial robot selection problem, their relative ranking performance are compared using the following measures:

(a) Spearman's rank correlation coefficient,

(b) Kendall's coefficient of concordance,

(c) Agreement between the top three ranked alternatives, and

(d) Number of ranks matched, as the percentage of the number of considered alternatives. 
Using Spearman's rank correlation coefficient $\left(r_{s}\right)$ value, the similarity between two sets of rankings can be measured (Sheskin, 2004). Usually, its value lies between -1 and +1 , where the value of +1 denotes a perfect match between two rank orderings. Table 21 shows the Spearman's rank correlation coefficients when the rankings of the alternative robots as obtained using all the ten MCDM methods are compared between themselves and also with respect to the rank ordering as derived by Rao (2007). It is observed that the $r_{s}$ value ranges between 0.5952 and 1.000 . The performance of WPM and TOPSIS methods are satisfactory with respect to $r_{s}$ value. Other MCDM methods also perform well. It is also observed that SAW is similar to GTMA and GRA, GTMA to GRA, and PROMETHEE II to ROVM with respect to their ranking performance. The relative performance of the ten MCDM methods with respect to the ranking of the alternative robots as obtained by Rao (2007) can also be visualized if another parameter $(Z)$ is introduced expressed as follows,

$$
\mathrm{Z}=\mathrm{r}_{\mathrm{s}} \sqrt{\mathrm{m}-1}
$$

Fig. 2 shows the $\mathrm{Z}$ values for all the considered MCDM methods and it reveals that WPM, TOPSIS and GRA are the best methods. On the other hand, ELECTRE II does not perform well due to its mathematical complexity.

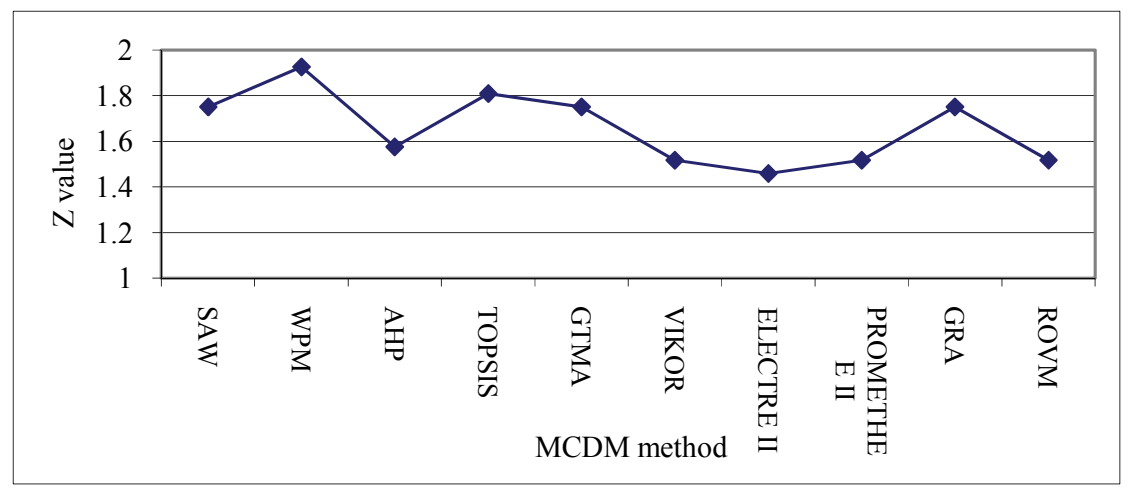

Fig. 2. $\mathrm{Z}$ values for different MCDM methods

The similarity of rankings obtained using the ten MCDM methods is also measured using Kendall's coefficient of concordance $(\mathrm{z})$ value which lies from 0 to 1 , where a value of 1 results in a perfect match (Hajkowicz \& Higgins, 2008). In this case, the value of Kendall's coefficient of concordance (z) is computed as 0.8583 , which suggests that there is an almost perfect agreement between the considered MCDM methods.

Table 21

Performance test results

\begin{tabular}{|c|c|c|c|c|c|c|c|c|c|c|}
\hline Method & SAW & WPM & AHP & TOPSIS & GTMA & VIKOR & ELECTRE II & PROMETHEE II & GRA & ROVM \\
\hline Rao (2007) & $\begin{array}{l}0.7143 \\
(\#, 2, \#, 57.14)\end{array}$ & $\begin{array}{l}0.7857 \\
(\#, 2, \#, 42.86)\end{array}$ & $\begin{array}{l}0.6429 \\
(\#, \#, \#, 42.86)\end{array}$ & $\begin{array}{l}0.7381 \\
(\#, 2, \#, 42.86)\end{array}$ & $\begin{array}{l}0.7143 \\
(\#, 2, \#, 57.14)\end{array}$ & $\begin{array}{l}0.6190 \\
(\#, \#, \#, 28.57)\end{array}$ & $\begin{array}{l}0.5952 \\
(\#, 2, \#, 42.86)\end{array}$ & $\begin{array}{l}0.6190 \\
(\#, \#, \#, 14.29)\end{array}$ & $\begin{array}{l}0.7143 \\
(\#, 2, \#, 57.14)\end{array}$ & $\begin{array}{l}0.6190 \\
(\#, \#, \#, 14.29)\end{array}$ \\
\hline SAW & & $\begin{array}{l}0.9762 \\
(1,2,3,71.43)\end{array}$ & $\begin{array}{l}0.9762 \\
(1, \#, \#, 71.43)\end{array}$ & $\begin{array}{l}0.9762 \\
(\#, \#, 3,51.43)\end{array}$ & $\begin{array}{l}1.0000 \\
(1,2,3,100)\end{array}$ & $\begin{array}{l}0.9048 \\
(1, \#, 3,71.43)\end{array}$ & $\begin{array}{l}0.9762 \\
(1,2,3,71.43)\end{array}$ & $\begin{array}{l}0.9524 \\
(1, \#, \#, 42.86)\end{array}$ & $\begin{array}{l}1.0000 \\
(1,2,3,100)\end{array}$ & $\begin{array}{l}0.9524 \\
(1, \#, \#, 42.86)\end{array}$ \\
\hline WPM & & & $\begin{array}{l}0.9524 \\
(1, \#, \#, 42.86)\end{array}$ & $\begin{array}{l}0.9524 \\
(\#, \#, 3,42.86)\end{array}$ & $\begin{array}{l}0.9762 \\
(1,2,3,71.43)\end{array}$ & $\begin{array}{l}0.8333 \\
(1, \#, 3,57.14)\end{array}$ & $\begin{array}{l}0.9286 \\
(1,2,3,57.14)\end{array}$ & $\begin{array}{l}0.9286 \\
(1, \#, \#, 14.29)\end{array}$ & $\begin{array}{l}0.9762 \\
(1,2,3,71.43)\end{array}$ & $\begin{array}{l}0.9286 \\
(1, \#, \#, 14.29)\end{array}$ \\
\hline AHP & & & & $\begin{array}{l}0.9286 \\
(\#, \#, \#, 57.14)\end{array}$ & $\begin{array}{l}0.9762 \\
(1, \#, \#, 71.43)\end{array}$ & $\begin{array}{l}0.9286 \\
(1, \#, \#, 57.14)\end{array}$ & $\begin{array}{l}0.9524 \\
(1, \#, \#, 42.86)\end{array}$ & $\begin{array}{l}0.9762 \\
(1,2,3,71.43)\end{array}$ & $\begin{array}{l}0.9762 \\
(1, \#, \#, 71.43)\end{array}$ & $\begin{array}{l}0.9762 \\
(1,2,3,71.43)\end{array}$ \\
\hline TOPSIS & & & & & $\begin{array}{l}0.9762 \\
(\#, \#, 3,71.43)\end{array}$ & $\begin{array}{l}0.8333 \\
(\#, \#, 3,57.14)\end{array}$ & $\begin{array}{l}0.9524 \\
(\#, \#, 3,42.86)\end{array}$ & $\begin{array}{l}0.9048 \\
(\#, \#, \#, 28.57)\end{array}$ & $\begin{array}{l}0.9762 \\
(\#, \#, 3,71.43)\end{array}$ & $\begin{array}{l}0.9048 \\
(\#, \#, \#, 28.57)\end{array}$ \\
\hline GTMA & & & & & & $\begin{array}{l}0.9048 \\
(1, \#, 3,71.43)\end{array}$ & $\begin{array}{l}0.9762 \\
(1,2,3,71.43)\end{array}$ & $\begin{array}{l}0.9524 \\
(1, \#, \#, 42.86)\end{array}$ & $\begin{array}{l}1.0000 \\
(1,2,3,100)\end{array}$ & $\begin{array}{l}0.9524 \\
(1, \#, \#, 42.86)\end{array}$ \\
\hline VIKOR & & & & & & & $\begin{array}{l}0.8810 \\
(1, \#, 3,42.86)\end{array}$ & $\begin{array}{l}0.9048 \\
(1, \#, 3,28.57)\end{array}$ & $\begin{array}{l}0.9048 \\
(1, \#, 3,71.43)\end{array}$ & $\begin{array}{l}0.9048 \\
(1, \#, \#, 28.57)\end{array}$ \\
\hline ELECTRE II & & & & & & & & $\begin{array}{l}0.9048 \\
(1, \#, \#, 28.57)\end{array}$ & $\begin{array}{l}0.9762 \\
(1,2,3,71.43)\end{array}$ & $\begin{array}{l}0.9048 \\
(1, \#, \#, 28.57)\end{array}$ \\
\hline PROMETHEE II & & & & & & & & & $\begin{array}{l}0.9524 \\
(1, \#, \#, 42.86)\end{array}$ & $\begin{array}{l}1.0000 \\
(1,2,3,100)\end{array}$ \\
\hline GRA & & & & & & & & & & $\begin{array}{l}0.9524 \\
(1, \#, \#, 42.86)\end{array}$ \\
\hline
\end{tabular}


Here, it does not matter which MCDM method has been used as the relative ranking will be more or less the same. As the decision maker may be sometimes interested to select the best robot as the single choice, another test is performed based on the agreement between the top three ranked robot alternatives. Here, a result of $(1,2,3)$ means the first, second and third ranks match; $(1,2, \#)$ means the first and second ranks match; $(1, \#, \#)$ means only the first ranks match; and (\#,\#,\#) means no match. Table 21 shows the results of this test which indicates that PROMETHEE II results in the maximum number of mismatches with respect to the ranking of the top three alternative robots. The last test is performed with respect to the number of ranks matched, expressed as the percentage of the number of alternatives considered. These values are also shown in Table 21. In this test, it is observed that GRA evolves out as the best MCDM method.

\section{Conclusions}

This paper studies the ranking performance of ten most well-known MCDM methods while solving an industrial robot selection problem. Four performance tests are conducted to measure the degree of agreement between the rankings derived by these MCDM methods. It is observed that although WPM, TOPSIS and GRA methods have slight advantage over the others, change of the MCDM method produces minor differences in the final ranking of the alternative robots. Thus, the rankings are not significantly affected by the choice of the MCDM method employed. The minor discrepancy that appears between the rankings obtained by different MCDM methods is only due to the difference in their mathematical modeling while solving a decision problem. Thus, the main focus must lie not on the selection of the most appropriate MCDM method to be adopted, but on proper structuring of the decision problem considering the relevant criteria and decision alternatives. The future scope of this paper may include comparing the relative permanence of the other newly developed MCDM methods, like Evamix, Regime, COPRAS (complex proportional assessment), LINMAP (linear programming technique for multi-dimensional analysis of preference) and NAIADE (novel approach to imprecise assessment and decision environments) while solving the robot selection problems.

\section{References}

Agrawal, V.P., Kohil, V., \& Gupta, A. (1991). Computer aided robot selection: the 'multiple attribute decision making' approach. International Journal of Production Research, 29, 1629-1644.

Baker, R.C., \& Talluri, S. (1997). A closer look at the use of data envelopment analysis for technology selection. Computers \& Industrial Engineering, 32, 101-108.

Behzadian, M., Kazemzadeh, R.B., Albadvi, A., \& Aghdasi, M. (2010). PROMETHEE: A comprehensive literature review on methodologies and applications. European Journal of Operational Research, 200, 198-215.

Bhangale, P.P., Agrawal, V.P., \& Saha, S.K. (2004). Attribute based specification, comparison and selection of a robot. Mechanism and Machine Theory, 39, 1345-1366.

Bhattacharya, A., Sarkar, B., \& Mukherjee, S.K. (2005). Integrating AHP with QFD for robot selection under requirement perspective. International Journal of Production Research, 43, 3671-685.

Braglia, M., \& Petroni, A. (1999) Evaluating and selecting investments in industrial robots. International Journal of Production Research, 37, 4157-4178.

Braglia, M., \& Gabbrielli, R. (2000). Dimensional analysis for investment selection in industrial robots. International Journal of Production Research, 38, 4843-4848.

Caterino, N., Iervolino, I., Manfredi, G., \& Cosenza, E. (2009). Comparative analysis of multi-criteria decision-making methods for seismic structural retrofitting. Computer-Aided Civil and Infrastructure Engineering, 24, 432-445.

Chatterjee, P., Athawale, V.M., \& Chakraborty, S. (2010). Selection of industrial robots using compromise ranking and outranking methods. Robotics and Computer-Integrated Manufacturing, 26, 483-489.

Chu, T-C., \& Lin, Y-C. (2003). A fuzzy TOPSIS method for robot selection. International Journal of Advanced Manufacturing Technology, 21, 284-290.

Goh, C-H., Tung, Y-C.A., \& Cheng, C-H. (1996). A revised weighted sum decision model for robot selection. Computers \& Industrial Engineering, 30, 193-199. 
Goh, C-H. (1997). Analytic hierarchy process for robot selection. Journal of Manufacturing Systems, 16, 381386.

Guitouni, A., \& Martel, J-M. (1998). Tentative guidelines to help choosing an appropriate MCDA method. European Journal of Operational Research, 109, 501-521.

Hajkowicz, S., \& Higgins, A. (2008). A comparison of multiple criteria analysis techniques for water resource management. European Journal of Operational Research, 184, 255-265.

Kahraman, C., Çevik, S., Ates, N.Y., \& Gülbay, M. (2007). Fuzzy multi-criteria evaluation of industrial robotic systems. Computers \& Industrial Engineering, 52, 414-433.

Karni, R., Sanchez, P., \& Rao Tummala, V.M. (1990). A comparative study of multiattribute decision making methodologies. Theory and Decision, 29, 203-222.

Karsak, E.E., \& Ahiska, S.S. (2005). Practical common weight multi-criteria decision-making approach with an improved discriminating power for technology selection. International Journal of Production Research, 43, 1537-1554.

Karsak, E.E. (2008). Robot selection using an integrated approach based on quality function deployment and fuzzy regression. International Journal of Production Research, 46, 723-738.

Kentli, A., \& Kar, A.K. (2011). A satisfaction function and distance measure based multi-criteria robot selection procedure. International Journal of Production Research, DOI: 10.1080/00207543.2010.530623.

Khouja, M. (1995). The use of data envelopment analysis for technology selection. Computers \& Industrial Engineering, 28, 123-132.

Khouja, M.J., \& Kumar, R.L. (1999). An options view of robot performance parameters in a dynamic environment. International Journal of Production Research, 37, 1243-1257.

Koulouriotis, D.E., \& Ketipi, M.K. (2011). A fuzzy digraph method for robot evaluation and selection. Expert Systems with Applications, doi: 10.1016/j.eswa.2011.03.082.

Kumar, R., \& Garg, R.K. (2010). Optimal selection of robots by using distance based approach method. Robotics and Computer-Integrated Manufacturing, 26, 500-506.

Opricovic, S., \& Tzeng, G.H. (2004). Compromise solution by MCDM methods: a comparative analysis of VIKOR and TOPSIS. European Journal of Operational Research, 156, 445-455.

Opricovic, S., \& Tzeng, G.H. (2007). Extended VIKOR method in comparison with outranking methods. European Journal of Operational Research, 178, 514-529.

Parkan, C., \& Wu, M-L. (1999). Decision-making and performance measurement models with applications to robot selection. Computers \& Industrial Engineering, 36, 503-523.

Raju, K.S., \& Pillai, C.R.S. (1999). Multicriterion decision making in river basin planning and development. European Journal of Operational Research, 112, 249-257.

Rao, R.V., \& Padmanabhan, K.K. (2006). Selection, identification and comparison of industrial robots using digraph and matrix methods. Robotics and Computer-Integrated Manufacturing, 22, 373-383.

Rao, R.V. (2007). Decision making in the manufacturing environment using graph theory and fuzzy multiple attribute decision making methods. London: Springer-Verlag.

Rao, R. V., \& Patel, B. K. (2009) Decision making in the manufacturing environment using an improved PROMETHEE method. International Journal of Production Research, 48, 4665-82.

Rao, R.V., Patel, B.K., \& Parnichkun, M. (2011). Industrial robot selection using a novel decision making method considering objective and subjective preferences. Robotics and Autonomous Systems, doi:10.1016/j.robot.2011.01.005

Roy, B., \& Vincke, P. (1981). Multi-criteria analysis: Survey and new directions. European Journal of Operational Research, 8, 207-218.

Saaty, T.L. (1980). The analytic hierarchy process. New York: McGraw-Hill.

Sheskin, D.J. (2004). Handbook of parametric and nonparametric statistical procedures. Chapman and Hall/CRC.

Singh, D., \& Rao, R.V. (2011). A hybrid multiple attribute decision making method for solving problems of industrial environment. International Journal of Industrial Engineering Computations, doi: 10.5267/j.ijiec.2011.02.001.

Talluri, S., \& Yoon, K.P. (2000). A cone-ratio DEA approach for AMT justification. International Journal of Production Economics, 66, 119-129.

Zanakis, S.H., Solomon, A., Wishart, N., \& Dublish, S. (1998). Multi-attribute decision making: A simulation comparison of select methods. European Journal of Operational Research, 107, 507-529.

Zeleny, M. (2002). Multiple criteria decision making. New York: McGraw Hill.

Zhao, L., Tsujimura, Y., \& Gen, M. (1996). Genetic algorithm for robot selection and work station assignment problem. Computers \& Industrial Engineering, 31, 599-602. 